\title{
Uridine-5'-tri-phosphate is a candidate component of the soluble sex pheromone bouquet in a marine shrimp, Lysmata wurdemanni
}

\author{
Dong Zhang ${ }^{1 *}$, Xin Liu ${ }^{1}$, Maggy A. Harley ${ }^{2}$, Jörg D. Hardege ${ }^{2^{*}}$ \\ ${ }^{1}$ East China Sea Fisheries Research Institute, Chinese Academy of Fisheries \\ Sciences, Shanghai 200090, P. R. China \\ ${ }^{2}$ Department of Biological and Marine Sciences, Hull University, Hull HU6 7RX, UK \\ *Corresponding author : zd_fit@hotmail.com, j.d.hardege@hull.ac.uk \\ Tel.: 86-21-65684655, Fax: 86-21-65683926
}

Declarations of interest: none 
ABSTRACT: Characterization of distance sex pheromone in decapods is still a challenge although great efforts have been made in this field in the past fifty years. In a previous study we identified a component of distance (soluble) sex pheromone bouquet of the peppermint shrimp Lysmata wurdemanni as a uridine-5'-di-phosphate (UDP)-like chemical. However, UDP does not elicit pre-copulatory behavior, approach and follow, in the peppermint shrimp. Here we tested the hypothesis that the UDP-like chemical is uridine-5'-tri-phosphate (UTP), a metabolic product from the shrimp's chitin synthesis, and is the component of the distance sex pheromone of the shrimp. We ran a series of bioassays to examine whether UDP, UTP or their mixtures elicit male mating behavior. Our results show that male $L$. wurdemanni responded to UTP through displaying their stereotyped courtship behaviour (approach and follow), same as the behaviour that water collected from moulting female elicits. Combining UTP and UDP as mixtures did not enhance the intensity of this male courtship behaviour. Minimum effective concentration of UTP to elicit the courtship behaviour in the male shrimp was between $10^{-6}$ and $10^{-7} \mathrm{M}$. HPLC analysis showed the existence of UTP in the moulting water of female shrimp and partial conversion of UTP to UDP during the sample preparation procedure. Both bioassay and chemical analysis results presented in this study suggest that UTP is a component of the distance sex pheromone in $L$. wurdemanni. The major peak of chromatogram of $L$. wurdemanni pheromone identified in previous studies might be a breakdown product of UTP.

KEY WORDS: Uridine-5'-tri-phosphate $\cdot$ Sex pheromone $\cdot$ Shrimp $\cdot$ Courtship behavior 


\section{INTRODUCTION}

In generally, females emit distance pheromone to attract mating partners in many decapod crustaceans, such as crabs (Ryan 1966, Gleeson 1980, Seifert 1982, Hardege et al. 2002, Kamio et al. 2002, 2014), lobsters (Atema 1984), crayfish (Ameyaw-Akumfi \& Hazlett 1975, Tierney et al. 1984, Stebbing et al. 2003), and several shrimp species in the genus Lysmata (Giri 2002, Zhang \& Lin 2006, Zhang et al. 2007, 2010, Zhang 2009), In Lysmata species, distance pheromone induces a pre-copulatory behaviour, i.e. searching behaviour (Zhang \& Lin 2006, Zhang 2009).

Efforts to characterise distance pheromones of crustaceans have been reported in lobster (Atema \& Gagosian 1973, Gagosian \& Atema 1973), crabs (Gleeson 1984, Asai et al. 2000, Hardege et al. 2002, 2011, Kamio et al. 2002, 2014) and amphipods Microdeutopus gryllotalpa (Borowsky et al. 1987). However, it is still a challenge work to purify and characterise such distance pheromones of decapod crustaceans. In recent years three chemicals, ceramides, uridine-5'-di-phosphatewere (UDP), and $\mathrm{N}$-acetylglucosamino-1,5-lactone (NAGL) were suggested as components of distance sex pheromone in decapod crustaceans. Although ceramides were suggested as the distance pheromones in the hair crab Erimacrus isenbeckii, this theory was not supported with behavioural data (Asai et al. 2000). UDP was identified to be the major component of the female crab pheromone and induced all key characteristics of male sexual behaviour in the shore crab Carcinus maenas (Hardege et al. 2011). UDP was able to elicit courtship in a number of crabs, including the snow crab Chionoecetes opilio and yellowline arrow 
crab Stenorhynchus sticornis (Bublitz et al. 2008, Fletcher \& Hardege 2009). Furthermore, a test demonstrates that uridine-5'-tri-phosphate (UTP) is probably a component of the sex pheromone bouquet in the crab C. maenas as well because it is able to elicit a stereotyped mating behaviour albeit at higher threshold concentrations than UDP (Fletcher 2007). In the blue crab Callinectes sapidus, another compound associated with moulting and chitin biosynthesis in crustaceans, NAGL, was considered as a candidate component of the courtship pheromone (Kamio et al. 2014). In a caridean shrimp Lysmata wurdemanni, the major component of the distance pheromone bouquet has been demonstrated to be a small molecule of approx. 500 - 1000 Dalton, whose UV spectrum is similar to UDP, but its chromatographic properties were not the same as UDP's (Zhang et al. 2010).

Both UTP and UDP are linked to the pathway of chitin biosynthesis (Stevenson 1972) in decapod crustaceans. The polymerization of chitin, a polymer of $\mathrm{N}$-acetyl- $\beta$-D-glucosamine (GlcNAc), requires UDP-GlcNAc as a substrate, which is synthesized from GlcNAc-1-phosphate and UTP (Stevenson 1972, Horst et al. 1993). Hence UTP and UDP might be released during moulting, one and/or both of them or their mixture may serve as distance sex pheromone (Fletcher 2007). In a previous study, we found the major component of the distance pheromone in L. wurdemanni might be a UDP-like chemical (Zhang et al. 2010). Alternatively, the UDP-like chemical is possibly a breakdown or metabolic product of UTP. UTP in solution is unstable and converts into UDP, resulting in UTP concentration too low to be detectible in the urine anymore. In the present study, we further identified the component of the distance sex pheromone in $L$. 
wurdemanni. We ran a series of bioassay to investigate whether $L$. wurdemanni induces courtship behavioural response to UTP and/or UDP and the effect of shrimp pheromone sample preparation process on UTP breakdown to establish a reliable procedure for the pheromone analysis of the shrimp, and probably for other decapod crustaceans.

Lysmata wurdemanni is a protandric simultaneous hermaphrodite (Bauer 2000). Male function matures first (male phase), i.e. testis portion mature first. the ovarian portion may develop (i.e. sex change) later as shrimp grow, so that the gonad can produce both eggs and sperm simultaneously, a condition called simultaneous hermaphrodite or euhermaphrodite (Bauer \& Holt 1998). The intermoult euhermaphrodite-phase shrimp functioning as a male can mate with the newly moulted euhermaphrodite-phase shrimp playing the female role. Pre-copulatory behaviour of male-role L. wurdemanni has been well described (Bauer \& Holt 1998, Zhang \& Lin 2004, 2006, Zhang et al. 2007, Zhang 2009). Pre-copulatory behaviour in L. wurdemanni is classified as searching behaviour since male are in continuous motion; this being interpreted a searching for a receptive female (Bauer \& Holt 1998, Zhang \& Lin 2004, 2006, Zhang et al. 2007). When male encounter a receptive female, copulation occurs almost immediately after a short interaction (Bauer \& Holt 1998, Zhang \& Lin 2004, 2006, Zhang et al. 2007). During the mating process of several studied Lysmata shrimp species, the soluble distance pheromones induce searching behaviour, and male depend on the contact pheromones coating on the cuticle surface to recognise a receptive female (Zhang \& Lin 2006, Zhang et al. 2011). Therefore, identifying the chemical characteristics of the distance sex pheromone in L. wurdemanni would give better understanding of reproductive behaviour 
in Lysmata shrimp. Moreover, because UDP, UTP, and NAGL are all involved in chitin biosynthesis of decapod crustaceans, the present study would give an insight into the distance pheromone metabolic mechanism in decapod crustaceans.

\section{MATERIALS AND METHODS}

\subsection{Experimental animal}

The experimental shrimp were bought from local aquarium stores. The shrimp were maintained in six flow-through tanks $(30 \times 20 \times 20 \mathrm{~cm})$, and fed squid or adult brine shrimp once daily. Salinity, temperature, light intensity and photoperiod were $35 \%$, 26-28 ${ }^{\circ} \mathrm{C}$ temperature, $1000 \mathrm{~lx}$ and $14 \mathrm{~h} \mathrm{~L} / 10 \mathrm{~h} \mathrm{D}$, respectively. All shrimp were fed ad libitum $1 \mathrm{~h}$ before used for bioassay.

\subsection{Chemical stimuli}

To determine whether uridine-5'-tri-phosphate (UTP), uridine-5'-di-phosphate (UDP), and their mixture can elicit pre-couplatory behaviour of male L. wurdemanni, the stock solutions (0.1 M) of UTP and UDP (purchased from Sigma-Aldrich Chemical Co., purity of 99\%) were prepared with deionized water, and their mixtures in three ratios $\left(80 \%\right.$ UTP $+20 \%$ UDP, $50 \%$ UTP $+50 \%$ UDP, $20 \%$ UTP $+80 \%$ UDP) at $10^{-4} \mathrm{M}$ were prepared with the stock solutions and natural seawater. Female conditioned seawater (500 ml) in which a euhermaphrodite-phase (EP) shrimp moulted was also tested. Regular seawater was used as control. To collect female conditioned seawater, a parturial (pre-spawning moult, and larvae hatched before the moult) EP shrimp in which larvae have hatched was maintained in a 11 beaker containing $500 \mathrm{ml}$ seawater for $2-3 \mathrm{hrs}$, 
which was stored at $-40^{\circ} \mathrm{C}$ freezer immediately after the shrimp moulted. In total, 40 shrimp moulting water were collected. As a control, 40 intermoult EP shrimp were housed in 51 seawater for $4 \mathrm{~h}$, then the conditioned water was collected. For HPLC analysis, the sample had to been concentrated and desalted. The frozen samples were thawed and filtered with an Amicon® stirred cell (500 Dalton, YC-05) ultra-filtration kit (250 $\mathrm{ml}$ in volume) at room temperature $\left(25^{\circ} \mathrm{C}\right)$. For each filtration, $200 \mathrm{ml}$ sample water was concentrated to about $15 \mathrm{ml}$ as pre-filtered sample. All pre-filtered samples were pooled together and stored at $-40^{\circ} \mathrm{C}$ freezer immediately for final concentration. All pre-filtered sample water was concentrated to about $15 \mathrm{ml}$, and thereafter desalted with double distilled water. On average, it took about $4 \mathrm{~h}$ to concentrate and desalt a sample of $200 \mathrm{ml}$.

\subsection{Bioassay of chemical stimuli}

Behavioural responses of the shrimps to soluble sex pheromones, as well as method for determining and scoring those behaviours were carried out as described in previous studies (Zhang \& Lin 2006, Zhang et al. 2010).. Thirty male-phase (MP) shrimp were used for each treatment or control and no individual shrimp was used more than once for individual treatment or control experiments. To simplify, the term male is used to represent male-role shrimp throughout the paper hereafter. Bioassays were conducted in rectangular tanks $(20 \times 40 \times 24 \mathrm{~cm})$ containing 61 of seawater (Fig. 1). One day before the observation, 2 males were acclimated in the tanks with aeration and fed with Artemia sp. nauplii. Regular seawater was presented first for several times to make the shrimps 
not fear the operation, after at least ten min interval, followed by the tested chemical compound (UDP, or UTP, or the UDP and UTP mixture), or female moulting water, or regular seawater (control). Tested stimuli and control were tested in separate tanks, respectively. The experimenter was undertaken blind with the observer not aware to the stimuli being tested. Water was added $\left(2-3\right.$ drops s$\left.^{-1}\right)$ near ( $4-5 \mathrm{~cm}$ away) the tested male through a siphon tube of $3.0 \mathrm{~mm}$ inside diameter. If the male approached the tube, then the tube was moved slowly around the male to determine whether the male would follow the tube. The shrimps' responses were recorded with a Sony camcorder and analysed. Full positive response of male shrimp was defined as both approach and follow: male would approach the tube and stay on the tube for several seconds to several tens of seconds, and some males may follow the movement of the tube. The behavioural responses to the sex stimuli were different from those to food stimulus (which was a supernatant of a homogenate of $2 \mathrm{~g}$ of shrimp abdominal muscle in $400 \mathrm{ml}$ of seawater). When males detected the food stimulus, shrimps rushed towards and might lifted somewhat claws and anterior part of the body towards the tube delivered the stimulus, and tried to grasp the tube. It is also known from other crustaceans that responses to feeding stimulants are much lower during the reproductive season, e.g. in shore crabs Carcinus maenas males prefer sex pheromones over feeding cues (Fletcher \& Hardege 2009) and rarely respond to food signals at all. Hence, all behaviours triggered by premoult female conditioned water and UTP are considered as courtship behaviours.

Minimum concentration at which shrimps responded to the compounds tested were determined. Because male shrimp did not respond to UDP (see the Results), only 
minimum UTP threshold concentrations to elicit behavioural responses in male shrimp was examined, which was done by determining the dose-response levels for 30 individuals. Shrimps were presented with log-step concentrations (descending from $10^{-4}$ M till no behavioural response displayed) of each individual chemical compound. Regular seawater was used as control.

Number of the male displaying positive response to stimuli was analyzed with Chi-squared test for $\mathrm{r} \times \mathrm{c}$ contingency table (SPSS statistical software, version 19.0, Chicago Illinois, USA).

\subsection{UTP breakdown/conversion}

To determine whether the UDP-like chemical that forms part of the distance pheromone is a breakdown or metabolite that stems from UTP, standard solutions of UTP were treated with a process similar to that of pheromone sample collection and preparation from female shrimp water. Ten $\mathrm{ml}$ of $10^{-4} \mathrm{M}$ UTP solution were prepared with seawater. To simulate the sample collection process, the solutions were placed at ambient temperature (about $25^{\circ} \mathrm{C}$ ) for about $2 \mathrm{~h}$, then stored at $-40^{\circ} \mathrm{C}$ for $10 \mathrm{~d}$, so. the UTP solutions were aged for $10 \mathrm{~d}$. To simulate the ultra-filtering process, the frozen solution was placed at ambient temperature for about $60 \mathrm{~min}$, thereafter stored at $-40^{\circ} \mathrm{C}$ for $7 \mathrm{~d}$, and this freezing-defreezing process was repeated once. Thereafter, the concentration and desalting procedure for the female moulting water with an Amicon ${ }^{\circledR}$ stirred cell (500 Dalton) ultra-filtration kit was applied for the UTP solution.

\subsection{Analysis of pheromonal samples, and UTP and UDP standards}

The pheromone containing samples from moulting female shrimps, intermoult EP conditioned water, aged UTP, and a series of freshly prepared UTP and UDP standards of $10^{-4}, 10^{-5}, 10^{-6}$, and $10^{-7} \mathrm{M}$ were subsequently analysed in triplicates using HPLC (Agilent

model 1100). For HPLC, a TSK gel ODS-80TM column $(250 \mathrm{~mm} \times 4.6 \mathrm{~mm} \mathrm{ID} \times 5 \mu \mathrm{m}$ 
particle size) (TOSOH Bioscience), at $30^{\circ} \mathrm{C}$, was used with two mobile phases, A: 20 $\mathrm{mM}$ t-Butylamine buffered with phosphoric acid to a pH of 6.8 , and B: $90 \%$ mobile phase A plus $10 \%$ HPLC grade methanol. The system was run (isocratic mode, $1.0 \mathrm{ml} \mathrm{min}{ }^{-1}$ ) on a gradient of 0 to $35 \mathrm{~min} 100 \% \mathrm{~A}$ to $100 \% \mathrm{~B}$, held for $15 \mathrm{~min}$ at $100 \% \mathrm{~B}$ with a total run time of 50 min. The system was then re-equilibrated for 10 min back to $100 \% \mathrm{~A}$. An Agilent Diode Array Detector (DAD, model G1315B) was used with UV absorbance spectra in scan mode at wave length $210 \mathrm{~nm}$. Sixty microlitres of the sample, UTP and UDP standards were loaded at $1 \mathrm{ml} \mathrm{min}^{-1}$.

Due to the UV spectra of the two peaks from female moulting water not being detectable (when the concentration of UDP and UTP is $\leq 10^{-6} \mathrm{M}$, their UV spectra would be distorted, even undetectable), UDP and UTP standard were added to prepared moulting water sample to see whether UDP and UTP peaks showed the same time as that of the peaks of the female moulting water samples.

\subsection{Ethical Note}

All applicable international, national, and/or institutional guidelines for the care and use of animals were followed.

\section{RESULTS}

Male shrimp approach behaviour showed a significant difference in degree of activation in males across the 7 stimuli tested (Chi-squared test, $X_{6}^{2}=146.844, \mathrm{p}<$ 0.0001; Fig. 2). Comparing to UTP (28 males), there was only 1 male Lysmata wurdemanni that displayed the stereotyped approach response to synthetic UDP solution (Fig. 2). Approach and follow behaviour showed a significant difference as well (Chi-squared test, $X_{6}^{2}=104.866, \mathrm{p}<0.0001 ;$ Fig. 2). All thirty males displayed approach 
to the fresh moulting water, 24 of which also displayed a full behavioural response, so showed both, approach and follow. Six males displayed this full response to the UTP (Fig. 2). The number of males responded to UTP solutions decreased with decreasing the cue concentration (Chi-squared test, $X_{4}{ }_{4},=80.217, \mathrm{p}<0.0001$; Fig. 3). Minimum effective concentration of UTP was between $10^{-6}$ and $10^{-7} \mathrm{M}$ (Fig. 3).

Freshly prepared UDP and UTP eluted at 17.01 and 24.29 min, respectively (Fig. 4A). There were three peaks from the synthetic UTP sample at $8.96 \mathrm{~min} 17.01 \mathrm{~min}$, and $24.29 \mathrm{~min}$, respectively. The peaks at $17.01 \mathrm{~min}$ and $24.29 \mathrm{~min}$ are corresponding to UDP and UTP, respectively (Fig. 4B). Two peaks at $17.01 \mathrm{~min}$ and $24.29 \mathrm{~min}$ were detected from EP moulting water (Fig. 4C), however, not from the intermoult EP shrimp conditioned water (Fig. 4D). Due to low concentration by breakdown, UV spectra of the two peaks from EP moulting water were not detectable. However, the peaks of UDP and UTP overlapped exactly two peaks of moulting water (Fig. 4E).

\section{DISCUSSION}

Both bioassay test and chemical results presented in this study suggest that UTP is a component of the soluble sex pheromone in the shrimp, Lysmata wurdemanni. UTP attracts male $L$. wurdemanni and elicits a stereotyped courtship behaviour, approach and follow, which is the same behaviour that female moulting water elicits (Zhang \& Lin 2006).

The chromatogram of the EP shrimp moulting water shows that the peak retention times (17.01 $\mathrm{min}$ and $24.29 \mathrm{~min}$ ) of the two peaks are exactly same as that of UDP and UTP (Figs. 4A, 4B, and 4C), suggesting that the two peaks are UDP and UTP. The present study shows explicitly that UTP broke down during sample preparation (Fig. 3B), so UDP presented in the EP shrimp moulting water is likely to be a breakdown product of UTP. UDP alone did not elicit the stereotyped courtship behaviour, and UDP did not 
enhance the male's behavioural responses to UTP, further suggesting that UDP is not a component of the distance sex pheromone. The breakdown of the nucleotide resulting in the additional product peaks also made the concentration of the components at $24.29 \mathrm{~min}$ too low to detect its UV spectrum. Even so, we still could safely assume that the component at 24.29 min from the shrimp moulting water is probably UTP with the peak time only, because the UTP peak overlapped exactly to the peak of the component (Fig. 4E). UTP is absent in the intermoult EP shrimp conditioned water (Fig. 4D), indicating that UTP is only released during moulting of EP shrimp.

The main breakdown product of UTP in the samples, UDP is known to be produced from UTP when UTP is in an extracellular environment (Ho et al. 2013) and has been found the main component of the sex pheromone bouquet in the shore crab, Carcinus maenas (Bublitz et al. 2008, Fletcher \& Hardege 2009), and it also evokes courtship behaviour in several other crab species, such as the snow crab (Chionoecetes opilio) and yellowline arrow crab (Stenorhynchus sticornis) (Bublitz et al. 2008). However, UDP did not elicit positive responses of male $L$. wurdemanni even when its concentration was at $10^{-4} \mathrm{M}$. This suggests that slightly different, but similar strategies in sex pheromones may have been developed in decapod crustaceans. Because both UTP and UDP are linked to the pathway of chitin biosynthesis during moulting process (Stevenson 1972), decapod crustaceans using UTP or UDP as sex pheromones might use one or the other, or the mixture of both as their sex pheromones. For example, UDP is the main component of the sex pheromone in Carcinus maenas (Bublitz et al. 2008), 
however, UTP also elicits courtship behaviour, and the strongest response was invoked by a ratio of UDP : UTP at $80: 20$ (Fletcher 2007).

Moreover, NAGL has been suggested as a candidate component of distance sex pheromone in some crabs (Kamio et al. 2002, 2014), and most recently, the molting biomarker molecule, 2-acetamido-2-deoxy-gluconic acid, isolated from urine of blue crabs and helmet crabs was identified (Kamio et al. 2017). Because UDP, UTP, and NAGL are all involved in chitin biosynthesis of decapod crustaceans, further studies should investigate distance pheromone metabolic mechanisms related to chitin and moult in decapod crustaceans.

Animal sex pheromones are generally composed of multiple components. Individual components of a pheromonal blend may not elicit behavioural activity, but their mixtures in different ratios may lead to highly specialized blends (Sorensen 1996). Sex pheromones are usually a species-specific blend, such as in insects (Glover et al. 1987, Christensen et al. 1989, Canci et al. 2006, Geiselhardt et al. 2008) and goldfish (Poling et al. 2001). In L. wurdemanni, mixing UTP and UDP seems to be the simplest way to form a blend, however, the mixtures of UTP and UDP used in our experiments did not show stronger combined effect on invoking male's approach behaviour. Alternatively, UTP might be an isomer or tautomer of the sex pheromone of the species if they use a single compound as sex pheromone. Furthermore, the number of the male shrimp that displayed full pre-copulatory response to EP moulting water is significantly higher than that to UTP, suggesting either the major component of the sex pheromone might be an isomer of UTP or there might be more than one active component, missing 
during sample purification, in the shrimp pheromone bouquet as well which needs to be investigated in the future. Because the major component of the shrimp's distance pheromone is not stable, new protocols need to be developed for complete identification of the pheromone components.

Result from the present study suggests that the minimum effective concentration of UTP for the male shrimp is between $10^{-6} \mathrm{M}$ and $10^{-7} \mathrm{M}$, which is similar to what was found in fish, shore crabs and polychaete worm pheromones (Zeeck et al 1998, Kasumyan 2004, Hardege et al 2011). Threshold concentrations of chemical substances,

which could evoke behavioral responses in fish usually range $10^{-6}-10^{-9} \mathrm{M}$ (Kasumyan 2004). Our study also indicates that UTP is not stable in seawater. Since the EP shrimp can only mate as female during short post-moult window (normally a few hours) and male shrimp rely on contact sex pheromones to detect receptive females (Zhang and Lin 2006), the short life time of UTP could avoid attracting male shrimp probably to reduce predation risk (cannibalism) during female's most vulnerable period, i.e. post-moult period.

\section{CONCLUSIONS}

Both bioassay and chemical test results presented in the current study suggest that UTP is a candiate component of the soluble sex pheromone bouquet in the shrimp Lysmata wurdemanni. UTP attracted male L. wurdemanni and led a stereotyped courtship behaviour, approach and follow, which is the same as the behaviour that pre-moult 
female conditioned water elicits. The major peak of chromatograms of $L$. wurdemanni pheromones previously identified might be a breakdown of UTP.

Acknowledgments. This study was funded by National Science Foundation of China (project number: 41276142). Part of the study is based on Dong Zhang's previous Ph.D. thesis work.

\section{LITERATURE CITED}

Ameyaw-Akumfi C, Hazlett BA (1975) Sex recognition in crayfish Procambarus clarkii. Science 190:1225-1226

Asai N, Fusetani N, Matsunaga S, Sasaki J (2000) Sex pheromones of the hair crab Erimacrus isenbeckii. Part 1: isolation and structures of novel cermaides. Tetrahedron $56: 9895-9899$

Atema J (1984) Review of sexual selection and chemical communication in the lobster, Homarus americanus. Can J Fish Aquatic Sci 43:2283-2290

Atema J, Gagosian RB (1973) Behavioral responses of male lobsters to ecdysones. Mar Behav Physiol 2:15-20

Bauer RT (2000) Simultaneous hermaphroditism in caridean shrimps: a unique and puzzling sexual system in the Decapoda. J Crust Biol 20:116-128

Bauer RT, Holt GJ (1998) Simultaneous hermaphroditism in the marine shrimp Lysmata wurdemanni (Caridea: Hippolytidae): an undescribed sexual system in the decapod Crustacea. Mar Biol 132:223-235 
Borowsky B, Augelli CE, Wilson SR (1987) Towards chemical characterization of waterborne pheromone of amphipod crustacean Microdeutopus gryllotalpa. J Chem Ecol 13:1673-1680

Bublitz R, Sainte-Marie B, Newcomb-Hodgetts C, Fletcher N, Smith M, Hardege JD (2008) Interspecific activity of sex pheromone of the European shore crab (Carcinus maenas). Behaviour 145:1465-1478

Christensen TA, Mustaparta H, Hilderbrand JG (1989) Discrimination of sex pheromone blends in the olfactory system of the moth. Chem Senses 14:463-477

Danci A, Gries R, Schaefer PW, Gries G (2006) Evidence for four component close-range sex pheromone in the parasitic wasp Glyptapanteles flavicoxis. J Chem Ecol 32:1539-54

Fletcher N (2007) Behavioural complexities in the European shore crab, Carcinus maenas. PhD thesis, University of Hull, Hull

Fletcher N, Hardege JD (2009) The cost of conflict: agonistic encounters influence responses to chemical signals in the shore crab, Carcinus maenas. Anim Behav $77: 357-361$

Gagosian RB, Atema J (1973) Behavioral responses of male lobsters to ecdysone metabolites. Mar Behav Physiol 2:115-120

Geiselhardt S, Jakobschy D, Ockenfels P, Peschke K (2008) A sex pheromone in the desert tenebrionid beetle Parastizopus armaticeps. J Chem Ecol 34:1065-1071 
Giri T (2002) Chemical detection of reproduction condition by the hermaphroditic shrimp Lysmata wurdemanni. Paper presented at the annual meeting of the Society for Integrative and Comparative Biology 2002, Anaheim

Gleeson RA (1980) Pheromone communication in the reproductive behavior of the crab, Callinectes sapidus. Mar Behav Physiol 7:119-134

Gleeson RA, Adams MA, Smith AB (1984) Characterization of a sex pheromone in the blue crab Callinectes sapidus. J Chem Ecol 10:913-921

Glover TJ, Tang XH, Roelofs WL (1987) Sex pheromone blend discrimination by male moths from E and Z strains of European corn borer. J Chem Ecol 13:143-151

Hardege JD, Jennings A, Hayden D, Müller CT, Pascore D, Bentley MG, Clare AS (2002) Novel behavioural assay and partial purification of a female-derived sex pheromone in Carcinus maenas. Mar Ecol Prog Ser 244:179-189

Hardege JD, Bartels-Hardege HD, Fletcher N, Terschak JA, Harley M, Smith MA, Davidson L, Hayden D, Müller CT, Lorch M, Welham K, Walther T, Bublitz R (2011) Identification of a female sex pheromone in Carcinus maenas. Mar Ecol Prog Ser 436:177-189

Ho CL, Yang CY, Lin WJ, Lin CH (2013) Ecto-nucleoside triphosphate diphosphohydrolase 2 modulates local ATP-induced calcium signaling in human HaCaT keratinocytes. PLoS One 8:e57666 
Horst MN, Walker AN, Klar E (1993) The pathway of crustacean chitin synthesis. In: MN Horst and JA Freeman (eds) Crustacean Integument: Morphology and Biochemistry. Boca Raton, FL: CRC Press, p 113-149

Kamio M, Matsunaga S, Fusetani N (2002) Copulation pheromone in the crab Telmessus cheiragonus (Brachyura: Decapoda). Mar Ecol Prog Ser 234:183-190

Kamio M, Schmidt M, Germann MW, Kubanek J, Derby CD (2014) The smell of moulting: $\mathrm{N}$-acetylglucosamino-1,5-lactone is a premoult biomarker and candidate component of the courtship pheromone in the urine of the blue crab, Callinectes sapidus. J Exp Biol 217:1286-1296

Kamio M, Nagakura Y, Yano H (2017) The molting biomarker molecule exists as 2-acetamido-2-deoxy-gluconic acid in urine of blue crabs and helmet crabs. Chem \& Biodivers 14: e1700063

Kasumyan AO (2004) The olfactory system in fish: structure, function, and tole in behavior. J Ichthyol, 44 (Suppl 2):S180-223

Poling KR, Fraser E, Sorensen PW (2001) The three steroidal components of the goldfish preovulatory pheromone signal evoke different behaviors in males. Comp Biochem Physiol B 129:645-651

Ryan EP (1966) Pheromone: evidence in a decapod crustacean. Science 151:340-341

Seifert P (1982) Studies on the sex pheromone of the shore crab, Carcinus maenas, with special regard to ecdysone excretion. Ophelia 21:147-158 
Sokal RR, Rohlf FJ (1995) Biometry. WH Freeman and Company, New York

Sorensen PW (1996) Biological responsiveness to pheromones provides fundamental and unique insight into olfactory function. Chem Sense 21:245-256

Stebbing PD, Bentley MG, Watson GJ (2003) Mating behaviour and evidence for a female released courtship pheromone in the signal Crayfish Pacifastacus leniusculus. J Chem Ecol 29:465-475

Stevenson JR (1972) Changing activities of the crustacean epidermis during the molting cycle. Am Zool 12:373-380

Tierney AJ, Thompson CS, Dunham EW (1984) Site of pheromone reception in the crayfish Orconectes propinquus (Decapoda, Cambaridae). J Crust Biol 4:554-559

Zeeck E, Harder T, Beckmann M (1998) Inosine, L-glutamic acid and L-glutamine as components of a sex pheromone complex of the marine polychaete Nereis succinea (Annelida: Polychaeta). Chemoecology 8:77-84

Zhang D (2009) Chemical communication and its ecological consequence in the Lysmata shrimp. PhD thesis, University of Hull, Hull

Zhang D, Lin J (2004) Fertilization success without anterior pleopods in shrimp Lysmata wurdemanni, a protandric simultaneous hermaphrodite (Crustacea: Decapoda: Caridea). J Crust Biol 24:470-473

Zhang D, Lin J (2006) Mate recognition in a simultaneous hermaphroditic shrimp, Lysmata wurdemanni (Caridea: Hippolytidae). Anim Behav 71:1191-1196 
Zhang D, Rhyne LA, Lin J (2007) Density-dependent effect on reproductive behaviour of Lysmata amboinensis and L. boggessi (Decapoda: Caridea: Hippolytidae). J Mar Biol Assoc UK 87:517-522

Zhang D, Lin J, Harley M, Hardege JD (2010) Characterization of a sex pheromone in a simultaneous hermaphroditic shrimp, Lysmata wurdemanni. Mar Biol 157:1-6

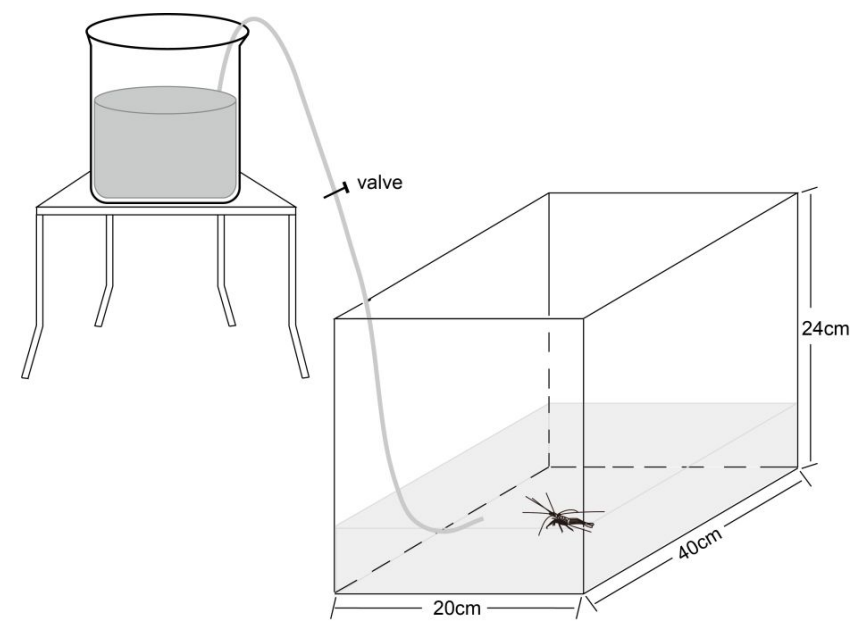


Fig. 1. Diagram of test tank $(20 \times 40 \times 24 \mathrm{~cm})$ containing 61 of seawater. Stimuli water was added (2 - 3 drops $\left.\mathrm{s}^{-1}\right)$ near (4 - $5 \mathrm{~cm}$ away) the tested male through a siphon tube of $3.0 \mathrm{~mm}$ inside diameter. 


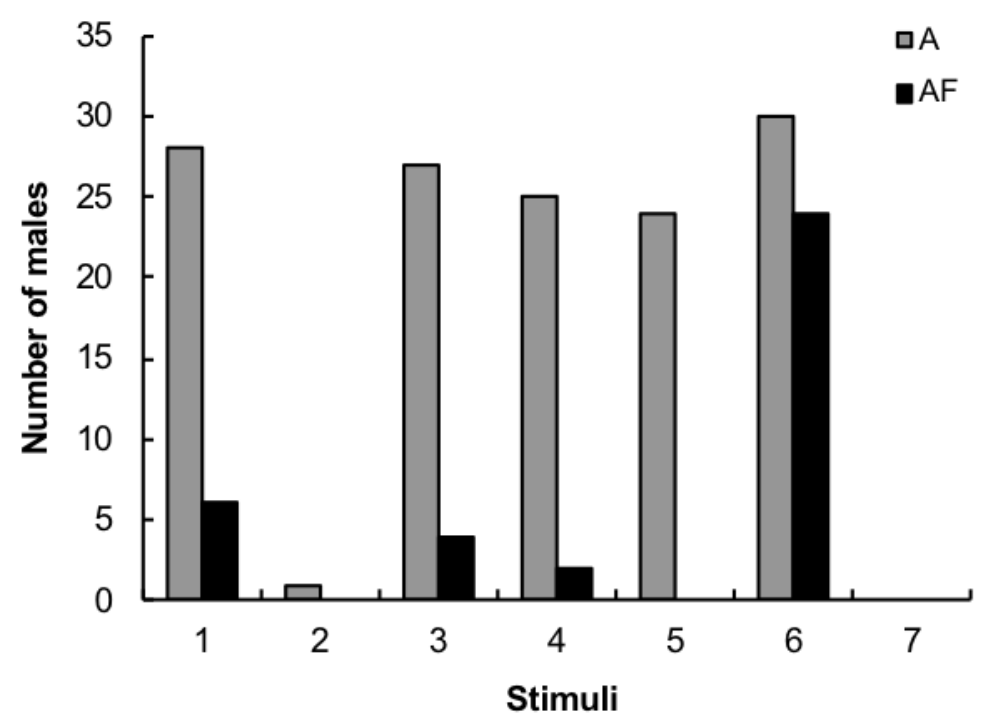

Fig. 2. Number of male Lysmata wurdemanni out of 30 responded to uridine-5'-tri-phosphate (UTP), uridine-5'-di-phosphate (UDP), the mixtures of UTP and UDP, female moulting water. $1=\mathrm{UTP}, 2=\mathrm{UDP}, 3=80 \% \mathrm{UTP}+20 \% \mathrm{UDP}, 4=50 \%$ $\mathrm{UTP}+50 \% \mathrm{UDP}, 5=20 \% \mathrm{UTP}+80 \% \mathrm{UDP}, 6=$ female moulting water, $7=$ regular seawater (control). $\mathrm{A}=$ approach, $\mathrm{AF}=$ approach and follow. Approach (Chi-squared test, $\left.X_{6}^{2}=146.844, \mathrm{p}<0.0001\right)$ approach and follow (Chi-squared test, $X^{2}{ }_{6}=104.866, \mathrm{p}<$ $0.0001)$ behaviours showed significant differences in degree of activation in males across the 7 stimuli tested. 


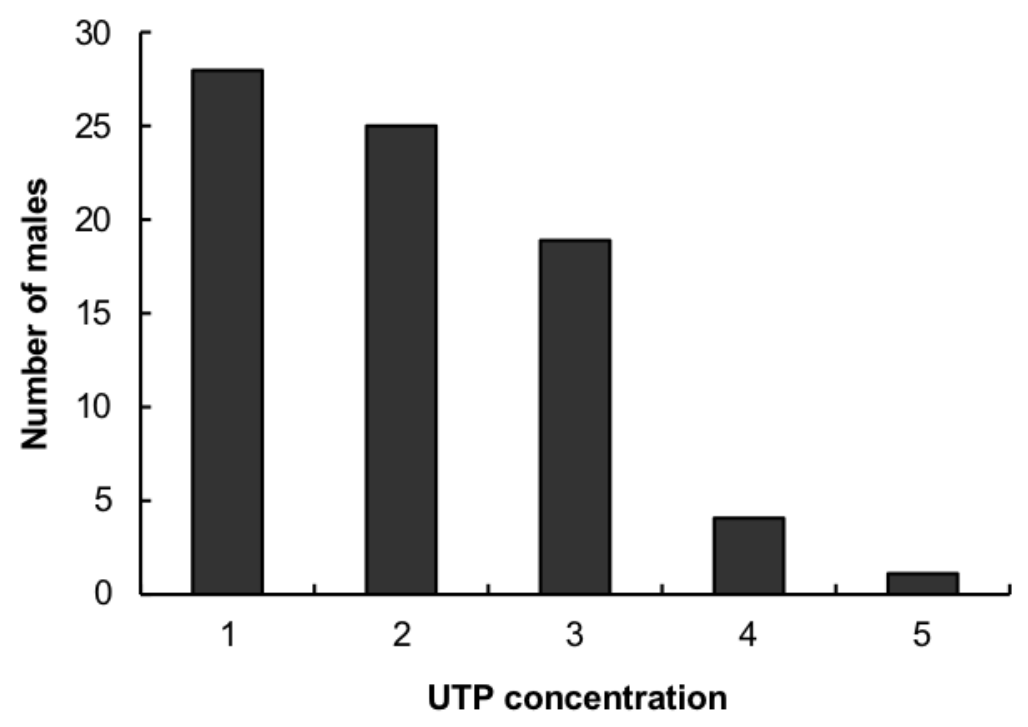

Fig. 3. Number of male Lysmata wurdemanni out of 30 responded to uridine-5'-tri-phosphate (UTP) of different concentrations. Shrimp only displayed approach behaviour to UTP. $1=10^{-4} \mathrm{M}, 2=10^{-5} \mathrm{M}, 3=10^{-6} \mathrm{M}, 4=10^{-7} \mathrm{M}, 5=$ Control (regular seawater). Number of males responded to UTP solutions decreased with the decreasing concentration (Chi-squared test, $X_{4}^{2}=80.217, \mathrm{p}<0.0001$ ). 

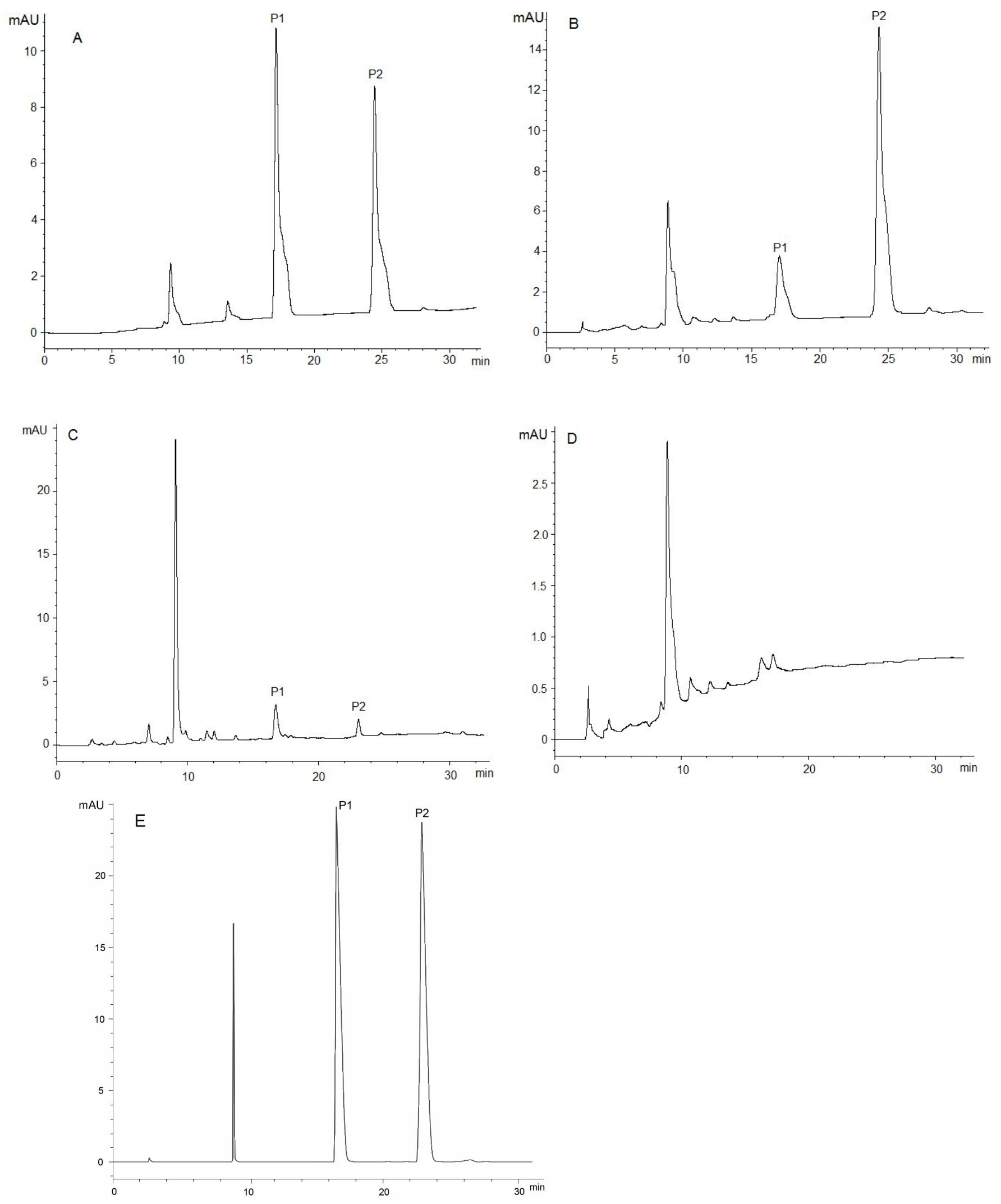
Fig. 4. HPLC-Chromatographs (at wave length $210 \mathrm{~nm}$ ) of newly prepared uridine-5'-di-phosphate (UDP) and uridine-5'-tri-phosphate (UTP) (A), aged UTP (B), female conditioned water (C), and intermoult euhermaphrodite-phase shrimp conditioned water (D), UTP and UDP added in female conditioned water (E). P1=UDP (17.01 min), P2=UTP $(24.29 \mathrm{~min})$. A TSK gel ODS-80TM column $(250 \mathrm{~mm} \times 4.6 \mathrm{~mm} \mathrm{ID} \times 5 \mu \mathrm{m}$ particle size) (TOSOH Bioscience), at $30^{\circ} \mathrm{C}$, was used with two mobile phases, A: 20 mM t-Butylamine buffered with phosphoric acid to a $\mathrm{pH}$ of 6.8 , and $\mathrm{B}: 90 \%$ mobile phase A plus $10 \%$ HPLC grade methanol. Concentration of P1 and P2 in Fig. 4C is about $10^{-7}$ M. 